\title{
Assessment of Biocompatibility of the Multilayer Flow Modulator with Differing Thread Designs
}

Sherif Sultan ${ }^{1,2 *}$, Edel P Kavanagh ${ }^{2}$, Michel Bonneau ${ }^{3}$, Chantal Kang ${ }^{3}$, Antoine Alves ${ }^{4}$ and Niamh Hynes ${ }^{2}$

${ }^{1}$ Department of Vascular and Endovascular Surgery, Western Vascular Institute, University Hospital Galway, Newcastle Road, Galway, Ireland

${ }^{2}$ Department of Vascular and Endovascular Surgery, Galway Clinic, Doughiska, Galway, Ireland

${ }^{3}$ Centre de Recherche en Imagerie Interventionnelle, National Institute of Agronomic Research, Jouy-en-Josas, France

${ }^{4}$ NAMSA, Chasse-sur-Rhône, France

\begin{abstract}
Background: The Multilayer Flow Modulator (MFM) (Cardiatis, Isnes, Belgium) is a self-expandable mesh of cobalt alloy wires used for the treatment of aortic aneurysms. The impact of design thread count and duration of implantation on the biocompatibility of the MFM in porcine animal models was assessed in this study.

Methods: Eight mini-piglets received 26 MFM devices (12 with 56 threads, 14 with 80-96 threads) in the iliac, carotid, and renal arteries. Animals were sacrificed and specimens explanted at 1, 3, and 6 months, at which time histological and ultrastructural analyses were carried out.

Results: The MFM was successfully deployed in 25 of the 26 implanted cases. The 56 thread devices were well tolerated locally and yielded fewer signs of inflammation and neo intimal hyperplasia. Percentage stenosis was $16.9 \% \pm 5.1 \%$ for the 56 thread devices versus $33.4 \% \pm 10.2 \%$ for the $80-96$ thread devices $(p=0.001)$ at 3 months, and $21.7 \% \pm 9.9 \%$ for the 56 thread devices versus $33.6 \% \pm 12.4 \%$ for the $80-96$ thread devices $(p=0.004)$ at 6 months. The 5 devices selected for SEM examination were well deployed, integrated into the vessel wall and endothelialized, and had patent side branches.

Conclusions: No significant stenosis formation or inflammatory response was recorded in any of the implanted animals. The 80-96 thread devices elicited a greater intra-arterial response than the 56 thread devices, although the values for both groups remained within the normal range for stented carotid, renal, or iliac arteries. Further preclinical and clinical studies will extend assessment of the long-term safety and effectiveness of the MFM.
\end{abstract}

Keywords: Multilayer flow modulator; Cobalt alloy stent; Thread design; Arterial disease; Biocompatibility

Abbreviations: MFM: Multilayer Flow Modulator; TAAA: Thoraco Abdominal Aortic Aneurysms; CE: Conformité Européenne; Cr2i: Centre de Recherche en Imagerie Interventionnelle; INRA: National Institute of Agronomic Research; SEM: Scanning Electron Microscopy

\section{Introduction}

Total exclusion of the aneurysm sac is the typical aim when stent grafts are deployed during endovascular repair. In treatment of thoraco abdominal aortic pathologies that would involve coverage of visceral arteries, fenestration holes and branching stent-grafts are placed in

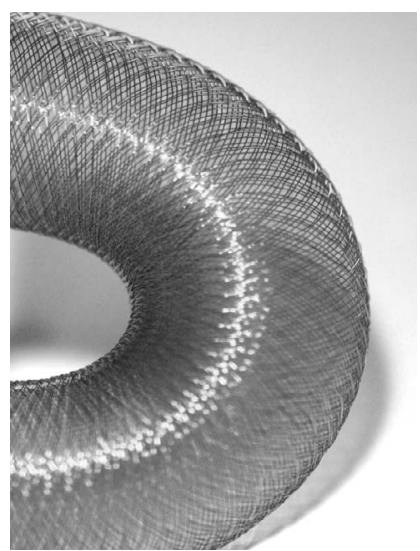

Figure 1: The Multilayer Flow Modulator (Cardiatis, Isnes, Belgium). the endografts to allow for collateral branch flow [1]. However, the branched and fenestrated graft technologies have been found to present considerable difficulty for operator utilization and require greater preoperative preparation in terms of artery and aneurysm morphologies [2]. An alternative approach to management of aortic aneurysms involves disruptive technology, in the form of the Multilayer Flow Modulator (MFM) (Cardiatis, Isnes, Belgium) [3]. The MFM is a self-expandable mesh of cobalt alloy wires interconnected in five layers (Figure 1). The MFM is extremely flexible with high resistance to kinking and fatigue. The MFM design allows blood flow through the mesh in a manner that maintains collateral branch patency, while modulating the flow from turbulent to laminar within the device and the aneurysm sac. Laminar flow in the aneurysm reduces shear stress on the aneurysm wall and encourages the formation of organized thrombus, thereby reducing risk of rupture. The MFM could represent a viable treatment alternative in complex arterial pathologies and in situations where open surgery or endovascular repair using a branched or fenestrated graft would not be feasible.

*Corresponding author: Sherif Sultan, Department of Vascular and Endovascular Surgery, Galway Clinic, Doughiska, Galway, Ireland, Tel: +35391720122; Fax: +35391785871; E-mail: sherif.sultan@hse.ie

Received November 21, 2014; Accepted November 27, 2014; Published November 29, 2014

Citation: Sultan S, Kavanagh EP, Bonneau M, Kang C, Alves A, et al. (2014) Assessment of Biocompatibility of the Multilayer Flow Modulator with Differing Thread Designs. J Vasc Med Surg 2: 167. doi: 10.4172/2329-6925.1000167

Copyright: @ 2014 Sultan S, et al. This is an open-access article distributed under the terms of the Creative Commons Attribution License, which permits unrestricted use, distribution, and reproduction in any medium, provided the original author and source are credited. 
The MFM has previously received Conformité Européenne (CE) marking for use in peripheral and aortic aneurysm repair. The device has since been implanted in numerous patients on compassionate grounds [4-8]. The MFM has been used successfully to treat renal artery aneurysms [4,5], visceral artery aneurysms [6], and aortic pathologies including TAAA and aortic type B dissections [3,7-9]. These retrospective studies reported successful treatment by reduction of flow velocity within the aneurysm sac while enhancing flow through branches, leading to the formation of organized thrombus. However, little is known in relation to the mechanisms of action of the MFM. This in vivo study focuses on the arterial biocompatibility of the MFM with differing thread designs, by evaluating histology and histomorphometry and performing ultrastructural analyses for 26 different device implantations in 8 porcine test animals.

\section{Materials and Methods}

\section{Ethics statement}

This prospectively designed study using porcine models was carried out at the Centre de Recherche en imagerie Intervention nelle (Cr2i) of the National Institute of Agronomic Research (INRA), Jouy-enJosas, France. Histological, histomorphometrical and ultrastructural analyses were performed by NAMSA, Chasse-sur-Rhone, France. All of the animals originated from the Bretoncelles breeding farm (Ferme des Noyers, F-61110, France). The study was conducted in accordance with EN IS0 10993-2:2006 Biological Evaluation of Medical DevicesPart 2: Animal Welfare Requirements, Directive 2010/63/EU on the protection of animals used for scientific purposes, and EN ISO 109936:2007 Biological Evaluation of Medical Devices -Part 6: Tests for local effects after implantation.

\section{Study preparation and design}

Eight porcine test animals (mini-piglets, average weight $44 \mathrm{~kg}$, average age 157 days) were selected for implantation of 26 MFM devices in the iliac, carotid, and renal arteries. The MFM design consisted of 56 threads in 12 devices, while 14 devices had a denser mesh consisting of 80 or 96 threads. The threads of the MFM are composed of Phynox medical grade B with an $80-\mu \mathrm{m}$ diameter, compliant with ASTM F1058-IS05832/7 standards. The study was designed to evaluate device performance in 3 durations of implantation: (1) 4 devices (2 with 56 threads and 2 with 80 threads) in 1 animal for 1 month; (2) 8 devices (4 with 56 threads and 4 with 80 threads) in 2 animals for 3 months; (3) 14 devices ( 6 with 56 threads, 3 with 80 threads, and 5 with 96 threads) in 5 animals for 6 months. Table 1 illustrates the distribution of the 26 MFM devices in the 8 animals, with respect to target arteries and durations of implantation.

Six technical success parameters were evaluated: (1) absence of dissection before and after device implantation as assessed by fluoroscopy and by visual examination after sacrifice; (2) accuracy of device positioning as assessed by fluoroscopy by comparing the position of the deployed device with the anatomical references previously chosen; (3) successful device deployment and expansion after delivery as assessed by arteriography immediately after implantation; (4) absence of immediate thrombosis within the device lumen as assessed by arteriography 5 to 10 minutes after MFM placement; (5) device visibility under angiographic monitoring at the time of sacrifice as rated by the operator on a 3-point scale, with $1=$ good, $2=$ fair, $3=$ not visible; and (6) absence of stenosis at the stent location as assessed by angiography on follow-up and before stent explantation.

\section{Implantation procedure}

The animals were anesthetized (ketamine10 $\mathrm{mg} / \mathrm{kg}$ ) and kept

\begin{tabular}{|c|c|c|c|c|}
\hline Animal & Implantation Artery & Device Number & Number of Device Threads & Duration of Implantation \\
\hline \multirow{4}{*}{ A } & right iliac & 1 & 56 & \multirow{4}{*}{1 month } \\
\hline & left carotid & 2 & 56 & \\
\hline & left iliac & 3 & 80 & \\
\hline & right carotid & 4 & 80 & \\
\hline \multirow{4}{*}{$\mathrm{B}$} & right iliac & 5 & 56 & \multirow{4}{*}{3 months } \\
\hline & left iliac* & 6 & 80 & \\
\hline & left renal & 7 & 56 & \\
\hline & left carotid & 8 & 80 & \\
\hline \multirow{4}{*}{$\mathrm{C}$} & right iliac * & 9 & 80 & \multirow{4}{*}{3 months } \\
\hline & left iliac & 10 & 80 & \\
\hline & right carotid & 11 & 56 & \\
\hline & left carotid & 12 & 56 & \\
\hline \multirow{3}{*}{$\mathrm{D}$} & right iliac* & 13 & 96 & \multirow{3}{*}{6 months } \\
\hline & right carotid & 14 & 96 & \\
\hline & left carotid & 15 & 56 & \\
\hline \multirow{3}{*}{$E$} & right iliac* & 16 & 80 & \multirow{3}{*}{6 months } \\
\hline & right carotid & 17 & 80 & \\
\hline & left carotid & 18 & 56 & \\
\hline \multirow{2}{*}{$\mathrm{F}$} & right iliac & 19 & 56 & \multirow{2}{*}{6 months } \\
\hline & left iliac* & 20 & 56 & \\
\hline \multirow{3}{*}{ G } & right iliac & 21 & 96 & \multirow{3}{*}{6 months } \\
\hline & left iliac & 22 & 96 & \\
\hline & common and left carotid & 23 & 96 & \\
\hline \multirow{3}{*}{$\mathrm{H}$} & right iliac & 24 & 80 & \multirow{3}{*}{6 months } \\
\hline & right carotid & 25 & 56 & \\
\hline & left carotid & 26 & 56 & \\
\hline
\end{tabular}

Table 1: Implantation Data ( ${ }^{*}$ Specimens selected for SEM examination). 
under general anesthesia with a supply of halothane $2 \%$. Oximetry and heart pulse rate were monitored throughout general anesthesia. MFM implantation was carried out under heparinization $(70 \mathrm{U} / \mathrm{kg}$ of non fractionated Choay heparin while implanting, $90 \mathrm{U} / \mathrm{kg}$ while explanting). Each procedure was performed witha new set of singleuse implantation devices: 7F Desilet introducer (Terumo, Corporate Office, 2101 Cottontail Lane, Somerset, NJ, USA), Terumo 0.025-inch guide wire, Cook 0.035-inch measuring guide wire (Bloomington, IN, USA). Percutaneous access was gained through the femoral artery using the Seldinger technique [10]. As crossing over was not possible, the devices were placed using a $7 \mathrm{~F}$ introducer in the right femoral artery for the right iliac and in the left femoral artery for the left iliac. All procedures were carried out under fluoroscopic monitoring using Telebrix 35 (Guerbet, BP 57400, 95943 Roissy CdG Cedex, France) contrast medium. Each animal received 2, 3, or 4 implants in the iliac and carotid arteries. One animal received a device in a renal artery. Assessment parameters and angiographic images were recorded at implantation and upon explantation.

\section{Post explantation evaluation}

Upon sacrifice of the animals, the stents and sections of the artery in which they were placed were explanted and prepared for gross examination, histological examination, histomorphometry and Scanning Electron Microscopy (SEM). Gross local intolerance criteria (inflammation, necrosis, hemorrhage) were evaluated and rated on a 5 -pointscale of severity: $0=$ absence; $1=$ slight; $2=$ moderate; $3=$ marked; $4=$ severe/full. After animal sacrifice, the explanted specimens were stored in $10 \%$ buffered formalin solution at room temperature $\left(+15^{\circ} \mathrm{C}\right.$ $\left.1+25^{\circ} \mathrm{C}\right)$. The specimens were dehydrated in alcohol solutions of increasing concentration, cleared with xylene, and finally embedded in polymethylmetacrylate. Proximal, medial, and distal sections were obtained for each specimen by a micro-cutting and grinding technique [11]. The proximal and distal sections were cut $5 \mathrm{~mm}$ from the edges of the MFM device. The sections were then stained with a modified paragon for qualitative and quantitative analysis. In addition, for the 3-month and 6-month time periods, two specimens were selected and a cross-section prepared from each for evaluation of patency and tissue reaction around the side branches.

The histological sections were observed under light microscopy using a Nikon Eclipse E600 microscope (Chiyoda, Tokyo, Japan) fitted with $\mathrm{x} 4, \mathrm{x} 10, \mathrm{x} 20$, and $\mathrm{x} 40$ objectives. A semi-quantitative histological evaluation was performed in adaptation to the IS0 109936 standard and state-of-the-art technique. The following parameters were assessed: inflammatory cells (macrophages, lymphocytes, giant cells), endothelialization, fibrin and thrombus deposits, neovessels, hyperplasia (neointimal thickness), neointimal cellularity, material degradation, integration of the device, protrusion, elastic lamina rupture, and medial thinning. Any relevant parameters were considered upon examination of the prepared slides and representative histological micrographs performed. Parameters were documented according to a 5 -point scale of severity: $0=$ absence; $1=$ slight; $2=$ moderate; $3=$ marked; $4=$ severe/full.

In a quantitative histomorphometrical analysis, the sections were observed using a Zeiss axioscope microscope fitted with $\mathrm{x} 5, \mathrm{x} 10$, $\mathrm{x} 20$, and $\mathrm{x} 40$ objectives and equipped with a color image analyzing system (Samba Technologies, France). Residual lumen surface and theoretical lumen area (corresponding to the initial lumen surrounded by the internal elastic lamina), stent, neointima, and media area were evaluated $\left(\mathrm{mm}^{2}\right)$. The mean neointimal thickness $(\mu \mathrm{m})$ of each arterial section was measured and the stenosis percentage was calculated as follows: $\%$ stenosis $=(\mathrm{N}+\mathrm{S}) /(\mathrm{N}+\mathrm{S}+\mathrm{RL}) \times 100$, where the neointima area $(\mathrm{N})$, stent area $(\mathrm{S})$, and residual lumen area $(\mathrm{RL})$ were measured in $\mathrm{mm}^{2}$. Statistical analysis (Mann \& Whitney test) was used for group and time period comparison.

Five specimens were chosen and biopsied for SEM analysis (as noted in Table 1). Two specimens were selected from the 3 -month time period, and 3 specimens from the 6 -month time period. The 5 biopsies were fixed in buffered glutaraldehyde solution, dehydrated in $20 \%$ acetone solution, submitted to the critical point process, and treated with gold palladium. SEM was performed using a Hitachi 8800 microscope (Chiyoda, Tokyo, Japan), under $15 \mathrm{KeV}$ voltage. SEM was conducted to evaluate the endothelial layer formation and the patency of the side branches on a 5-point index: $0=$ absence; $1=$ slight; $2=$ moderate; $3=$ marked; $4=$ severe/full.

\section{Results}

\section{Implantation}

Implantation results for each animal (animals A through $\mathrm{H}$ ) are recorded in Table 2 with the following main results noted. For animal A, the distal extremities of devices 2 and 4 were slightly narrowed after deployment, and angioplasty was subsequently performed to assist expansion. While a slight narrowing was observed in the distal sections of devices 11 and 12 in animal C, they were not inflated via angioplasty. The neck of the collateral artery on the right iliac (right iliac circumflex) was covered by device 9. In animal $\mathrm{F}$ accidental dissection of the right femoral artery occurred while placing the introducer. This dissection in turn caused a significant spasm in the right iliac artery, but device 19 was nevertheless implanted there successfully. The necks of both right and left iliac collateral arteries (right and left iliac circumflexes) were covered by devices 19 and 20. For animal G, the necks of both right and left iliac collateral arteries (right and left iliac circumflexes) were covered by devices 21 and 22 . The failure of device 23 to deploy correctly from its sheath resulted in stent migration to the trunk, common to the 2 primary carotids, while the introducer catheter was being removed. Device 23 was consequently excluded from the study.

\section{Explantation}

Explantation results for each animal (animals A through $\mathrm{H}$ ) are recorded in Table 2. An error in manipulating the anesthesia machine resulted in the death of the animal A before final angiography could be performed. As a result of this error, the right iliac and left carotid arteries, containing the 56 thread devices, were lost. The remaining anatomical parts (right carotid and left iliac), containing the 80 thread devices, were stored for histological examination. Patency of the iliac branches was observed upon explantation. Slight to moderate stenosis was observed in the implanted arteries of several of the animals, but all remained patent, including the necks of collateral arteries.

\section{Gross examination}

Before any histology was carried out, the outer aspects of the specimens (at 1, 3, and 6 months post implantation) underwent a gross examination to identify any local intolerances. Table 3 presents the means of ratings on the 5-point scale for the parameters in the quantitative gross examination. The following results were noted: Local inflammation was observed in 1 specimen implanted with an80-96 thread device. Slight necrosis was observed in 3 specimens ( 1 implanted with a56 thread device, and 2 implanted with 80-96 thread devices). Moderate necrosis was observed in 2 specimens, both implanted with 80-96 thread devices. Slight hemorrhage was evident in 9 specimens 
Citation: Sultan S, Kavanagh EP, Bonneau M, Kang C, Alves A, et al. (2014) Assessment of Biocompatibility of the Multilayer Flow Modulator with Differing Thread Designs. J Vasc Med Surg 2: 167. doi: 10.4172/2329-6925.1000167

Page 4 of 8

\begin{tabular}{|c|c|c|c|c|c|c|c|c|c|c|c|c|c|c|c|c|c|c|c|c|c|c|c|c|c|c|}
\hline \multicolumn{27}{|c|}{ IMPLANTATION } \\
\hline Animal & \multicolumn{4}{|c|}{ A } & \multicolumn{4}{|c|}{ B } & \multicolumn{4}{|c|}{ C } & \multicolumn{3}{|c|}{ D } & \multicolumn{3}{|c|}{ E } & \multicolumn{2}{|c|}{$\mathbf{F}$} & \multicolumn{3}{|c|}{ G } & \multicolumn{3}{|c|}{$\mathbf{H}$} \\
\hline Device & 1 & 2 & 3 & 4 & 5 & 6 & 7 & 8 & 9 & 10 & 11 & 12 & 13 & 14 & 15 & 16 & 17 & 18 & 19 & 20 & 21 & 22 & 23 & 24 & 25 & 26 \\
\hline $\begin{array}{l}\text { Successful device } \\
\text { placement }\end{array}$ & $\mathrm{Y}$ & $\mathrm{Y}$ & $\mathrm{Y}$ & $\mathrm{Y}$ & $\mathrm{Y}$ & $\mathrm{Y}$ & $\mathrm{Y}$ & $\mathrm{Y}$ & $\mathrm{Y}$ & $\mathrm{Y}$ & $\mathrm{Y}$ & $\mathrm{Y}$ & $\mathrm{Y}$ & $\mathrm{Y}$ & $\mathrm{Y}$ & $\mathrm{Y}$ & $\mathrm{Y}$ & $\mathrm{Y}$ & $\mathrm{Y}$ & $\mathrm{Y}$ & $\mathrm{Y}$ & $\mathrm{Y}$ & $\mathrm{N}$ & $\mathrm{Y}$ & $\mathrm{Y}$ & $Y$ \\
\hline Dissection while placing & $\mathrm{N}$ & $\mathrm{N}$ & $\mathrm{N}$ & $\mathrm{N}$ & $\mathrm{N}$ & $\mathrm{N}$ & $\mathrm{N}$ & $\mathrm{N}$ & $\mathrm{N}$ & $\mathrm{N}$ & $\mathrm{N}$ & $\mathrm{N}$ & $\mathrm{N}$ & $\mathrm{N}$ & $\mathrm{N}$ & $\mathrm{N}$ & $\mathrm{N}$ & $\mathrm{N}$ & Y & $\mathrm{N}$ & $\mathrm{N}$ & $\mathrm{N}$ & $\mathrm{Y}$ & $\mathrm{N}$ & $\mathrm{N}$ & $\mathrm{N}$ \\
\hline $\begin{array}{l}\text { Successful device } \\
\text { release }\end{array}$ & $\mathrm{Y}$ & $\mathrm{Y}$ & $\mathrm{Y}$ & $\mathrm{Y}$ & $\mathrm{Y}$ & $\mathrm{Y}$ & $\mathrm{Y}$ & $\mathrm{Y}$ & $\mathrm{Y}$ & $\mathrm{Y}$ & $\mathrm{Y}$ & $\mathrm{Y}$ & $\mathrm{Y}$ & $\mathrm{Y}$ & $\mathrm{Y}$ & $\mathrm{Y}$ & $\mathrm{Y}$ & $\mathrm{Y}$ & $\mathrm{Y}$ & $\mathrm{Y}$ & $\mathrm{Y}$ & $\mathrm{Y}$ & $\mathrm{N}$ & $\mathrm{Y}$ & Y & $\mathrm{Y}$ \\
\hline Positioning accuracy & $\mathrm{Y}$ & $\mathrm{Y}$ & $\mathrm{Y}$ & $\mathrm{Y}$ & $\mathrm{Y}$ & $\mathrm{Y}$ & $\mathrm{Y}$ & $\mathrm{Y}$ & $\mathrm{Y}$ & $\mathrm{Y}$ & $\mathrm{Y}$ & $\mathrm{Y}$ & $\mathrm{Y}$ & $\mathrm{Y}$ & $\mathrm{Y}$ & $\mathrm{Y}$ & $\mathrm{Y}$ & $\mathrm{Y}$ & $\mathrm{Y}$ & $\mathrm{Y}$ & $\mathrm{Y}$ & $\mathrm{Y}$ & $\mathrm{Y}$ & $\mathrm{Y}$ & $\mathrm{Y}$ & $\mathrm{Y}$ \\
\hline Successful deployment & $\mathrm{Y}$ & $Y^{*}$ & $\mathrm{Y}$ & $Y^{*}$ & $\mathrm{Y}$ & $\mathrm{Y}$ & $\mathrm{Y}$ & $\mathrm{Y}$ & $\mathrm{N}$ & $\mathrm{N}$ & $\mathrm{N}$ & $\mathrm{N}$ & Y & Y & $\mathrm{Y}$ & $\mathrm{Y}$ & $\mathrm{Y}$ & $\mathrm{Y}$ & $\mathrm{N}$ & $\mathrm{N}$ & Y & $\mathrm{Y}$ & $N^{* *}$ & $\mathrm{Y}$ & Y & $\mathrm{Y}$ \\
\hline Absence of thrombus & $\mathrm{Y}$ & $\mathrm{Y}$ & $\mathrm{Y}$ & $\mathrm{Y}$ & $\mathrm{Y}$ & $\mathrm{Y}$ & $\mathrm{Y}$ & $\mathrm{Y}$ & $\mathrm{Y}$ & $\mathrm{Y}$ & $\mathrm{Y}$ & $\mathrm{Y}$ & $\mathrm{Y}$ & $\mathrm{Y}$ & $\mathrm{Y}$ & $\mathrm{Y}$ & $\mathrm{Y}$ & $\mathrm{Y}$ & $\mathrm{Y}$ & $\mathrm{Y}$ & $\mathrm{Y}$ & $\mathrm{Y}$ & $\mathrm{Y}$ & $\mathrm{Y}$ & $\mathrm{Y}$ & $\mathrm{Y}$ \\
\hline $\begin{array}{l}\text { Length }(\mathrm{L}) \text { \& diameter } \\
(\varnothing) \text { of deployed device } \\
(\mathrm{mm})\end{array}$ & $\begin{array}{c}\text { L } 40 \\
\varnothing \\
6\end{array}$ & $\begin{array}{c}\text { L } 30 \\
\varnothing \\
6\end{array}$ & $\begin{array}{c}\text { L } 40 \\
\varnothing \\
7\end{array}$ & $\begin{array}{c}\text { L } 30 \\
\varnothing \\
7\end{array}$ & $\begin{array}{c}\mathrm{L} 25 \\
\varnothing \\
6\end{array}$ & $\begin{array}{c}\text { L } 30 \\
\varnothing \\
7\end{array}$ & $\begin{array}{c}\mathrm{L} 25 \\
\varnothing \\
6\end{array}$ & $\begin{array}{c}\text { L } 30 \\
\varnothing \\
7\end{array}$ & $\begin{array}{c}\text { L } 30 \\
\varnothing \\
7\end{array}$ & $\begin{array}{c}\text { L } 40 \\
\varnothing \\
7\end{array}$ & $\begin{array}{c}\mathrm{L} 25 \\
\varnothing \\
6\end{array}$ & $\begin{array}{c}\text { L } 35 \\
\varnothing \\
6\end{array}$ & $\begin{array}{c}\text { L } 50 \\
\varnothing \\
7\end{array}$ & $\begin{array}{c}\mathrm{L} 50 \\
\varnothing \\
5.5\end{array}$ & $\begin{array}{c}\mathrm{L} \\
30 \\
\varnothing 7\end{array}$ & $\begin{array}{c}\text { L } 30 \\
\varnothing \\
6\end{array}$ & $\begin{array}{c}\text { L } 30 \\
\varnothing \\
6\end{array}$ & $\begin{array}{c}\mathrm{L} \\
50 \\
\varnothing \\
5.5\end{array}$ & $\begin{array}{c}\mathrm{L} 20 \\
\varnothing \\
5.5\end{array}$ & $\begin{array}{c}\mathrm{L} 30 \\
\varnothing \\
5.5\end{array}$ & $\begin{array}{c}\mathrm{L} 50 \\
\varnothing \\
7\end{array}$ & $\begin{array}{c}\text { L } 50 \\
\varnothing \\
7\end{array}$ & $\begin{array}{l}\text { L } 50 \\
\varnothing \\
7\end{array}$ & $\begin{array}{c}\mathrm{L} 40 \\
\varnothing \\
7\end{array}$ & $\begin{array}{c}\text { L } 30 \\
\varnothing \\
6\end{array}$ & $\begin{array}{c}\mathrm{L} 25 \\
\varnothing \\
6\end{array}$ \\
\hline Device-to-artery ratio & 1.25 & 1.09 & 1.21 & 1.13 & 1.18 & 1.26 & 1.25 & 1.12 & 1.31 & 1.23 & 1.07 & 1.09 & 1.21 & 0.95 & 1.2 & 1.04 & 1.15 & 1.1 & 0.94 & 0.96 & 1.24 & 1.17 & 1.27 & 1.69 & 1.07 & 1.09 \\
\hline \multicolumn{27}{|c|}{ EXPLANTATION } \\
\hline Duration & \multicolumn{4}{|c|}{1 month } & \multicolumn{4}{|c|}{3 months } & \multicolumn{4}{|c|}{3 months } & \multicolumn{3}{|c|}{6 months } & \multicolumn{3}{|c|}{6 months } & \multicolumn{2}{|c|}{6 months } & \multicolumn{3}{|c|}{6 months } & \multicolumn{3}{|c|}{6 months } \\
\hline Device visibility*** & 2 & - & 2 & - & 2 & 2 & 3 & 2 & 2 & 2 & 2 & 2 & 2 & 2 & 2 & 2 & 2 & 2 & 2 & 2 & 2 & 2 & - & 2 & 2 & - \\
\hline Total thrombosis & $\mathrm{N}$ & $\mathrm{N}$ & $\mathrm{N}$ & $\mathrm{N}$ & $\mathrm{N}$ & $\mathrm{N}$ & $\mathrm{N}$ & $\mathrm{N}$ & $\mathrm{N}$ & $\mathrm{N}$ & $\mathrm{N}$ & $\mathrm{N}$ & $\mathrm{N}$ & $\mathrm{N}$ & $\mathrm{N}$ & $\mathrm{N}$ & $\mathrm{N}$ & $\mathrm{N}$ & $\mathrm{N}$ & $\mathrm{N}$ & $\mathrm{N}$ & $\mathrm{N}$ & - & $\mathrm{N}$ & $\mathrm{N}$ & - \\
\hline
\end{tabular}

Table 2: Implantation/Explantation Results ( ${ }^{*}$ Adjunctive balloon angioplasty to assist device expansion. ${ }^{* *}$ Device excluded from the study. ${ }^{* *} A$ rating of 1,2 , or 3 was given by the operator to indicate device visibility under angiographic monitoring at the time of sacrifice: $1=$ good; $2=$ fair; $3=$ not visible).

\begin{tabular}{|c|c|c|c|c|c|}
\hline & \multicolumn{3}{|c|}{ Device Thread Group } \\
\hline Parameters & \multicolumn{2}{|c|}{$\mathbf{5 6}$ Threads } & \multicolumn{2}{c|}{$\mathbf{8 0 - 9 6}$ Threads } \\
\hline Duration of implantation & 3 months & 6 months & 1 month & 3 months \\
\hline Inflammation & 0 & 0 & 0 & 0 \\
\hline Necrosis & 0.7 & 0.2 & 0.5 & 1.0 \\
\hline Hemorrhage & 0.8 & 0.2 & 1.0 & 0.1 \\
\hline
\end{tabular}

Table 3: Mean Quantitative Gross Examination*(*Mean of ratings on a 5-point scale: $0=$ absence; $1=$ slight; $2=$ moderate; $3=$ marked; $4=$ severe/full).

\begin{tabular}{|c|c|c|c|c|c|}
\hline \multirow{3}{*}{$\begin{array}{c}\text { Parameters } \\
\text { Duration of implantation }\end{array}$} & \multicolumn{5}{|c|}{ Device Thread Group } \\
\hline & \multicolumn{2}{|c|}{56 Threads } & \multicolumn{3}{|c|}{ 80-96 Threads } \\
\hline & 3 months & 6 months & 1 month & 3 months & 6 months \\
\hline Elastic lamina rupture & 1.6 & 0.5 & 0.3 & 1.3 & 1.4 \\
\hline Mural thrombus & 0.7 & 0.1 & 0.7 & 0.3 & 0.2 \\
\hline Fibrin deposit & 0.3 & 0.2 & 0.5 & 0.6 & 0.4 \\
\hline Lymphocytes & 0.3 & 0.1 & 0.7 & 0.6 & 0.2 \\
\hline Necrosis & 0 & 0 & 0 & 0.3 & 0 \\
\hline Macrophages & 0.9 & 1.1 & 1.3 & 1.5 & 1.5 \\
\hline Giant cells & 0.2 & 0.4 & 0.3 & 0.6 & 0.4 \\
\hline Neovessels & 0.2 & 0.5 & 0 & 1.3 & 1.1 \\
\hline Neointimal thickness & 1.0 & 1.2 & 1.5 & 1.9 & 1.5 \\
\hline Neointimal cellularity & 1.0 & 2.4 & 2.2 & 1.8 & 2.5 \\
\hline Stent integration & 4.0 & 3.8 & 4.0 & 3.9 & 3.9 \\
\hline Stent protrusion & 0.3 & 0.4 & 0 & 0.3 & 0.4 \\
\hline Endothelialization & 2.0 & 2.0 & 2.0 & 2.0 & 2.0 \\
\hline Medial thinning & 2.9 & 0.9 & 0.8 & 1.3 & 1.1 \\
\hline Material degradation & 0 & 0 & 0 & 0.1 & 0 \\
\hline
\end{tabular}

Table 4: Mean Semi-Quantitative Histopathological Analysis* ( ${ }^{\star}$ Mean of ratings on a 5-point scale: $0=$ absence; $1=$ slight; $2=$ =moderate; $3=$ marked; $4=$ severe/full).

(4 were implanted with 56 thread devices, and 5 implanted with 80-96 thread devices). Moderate hemorrhage was observed in 4 specimens, all implanted with 80-96 thread devices.

\section{Histopathological analysis}

The histopathological parameters were analyzed according to the number of threads attributed to each device and according to the duration of implantation. Table 4 presents the means of ratings on the 5-point scale for the parameters in the semi-quantitative histopathological analysis.
Following 3 months of implantation, the 56 thread devices were completely integrated into the vessels with a moderate grade of endothelialization. Frequent thin thrombus deposits were observed, and inflammatory reactions were either absent or rated as moderate in grade. After 6 months of implantation, the 56 thread devices were completely integrated into the vessels with a moderate grade of endothelialization. There was barely any thrombus deposits, and the neointimal thickness had not significantly changed compared to the findings in the specimens explanted after 3 months. At 6 months for the 56 thread devices, there was an overall slight grade of macrophagic and giant cell reaction, with 3 specimens showing a moderate grade 


\begin{tabular}{|c|c|c|c|c|c|}
\hline \multirow{3}{*}{$\begin{array}{c}\text { Parameters } \\
\text { Duration of implantation }\end{array}$} & \multicolumn{5}{|c|}{ Device Thread Group } \\
\hline & \multicolumn{2}{|c|}{56 Threads } & \multicolumn{3}{|c|}{ 80-96 Threads } \\
\hline & 3 months & 6 months & 1 month & 3 months & 6 months \\
\hline Neointimal area $\left(\mathrm{mm}^{2}\right)$ & $4.3 \pm 1.7$ & $5.2 \pm 3.2$ & $8.3 \pm 3.8$ & $7.0 \pm 4.5$ & $6.1 \pm 3.60$ \\
\hline Media area $\left(\mathrm{mm}^{2}\right)$ & $2.4 \pm 0.7$ & $2.2 \pm 0.5$ & $2.9 \pm 0.7$ & $2.4 \pm 0.6$ & $2.4 \pm 0.8$ \\
\hline Theoretical lumen area $\left(\mathrm{mm}^{2}\right)$ & $27.0 \pm 5.7$ & $25.1 \pm 7.1$ & $28.9 \pm 3.2$ & $20.7 \pm 8.9$ & $19.6 \pm 8.1$ \\
\hline Neointimal thickness $(\mu \mathrm{m})$ & $252.4 \pm 87.3$ & $311.3 \pm 162.7$ & $482.8 \pm 198.1$ & $460.6 \pm 232.1$ & $448.8 \pm 206.4$ \\
\hline Stenosis $(\%)$ & $16.9 \pm 5.1$ & $21.7 \pm 9.9$ & $29.3 \pm 10.4$ & $33.4 \pm 10.2$ & $33.6 \pm 12.4$ \\
\hline
\end{tabular}

Table 5: Mean ( \pm SD) Quantitative Histomorphometry Values.

\begin{tabular}{|c|c|c|c|c|c|}
\hline Duration of implantation & \multicolumn{2}{|c|}{3 months } & \multicolumn{2}{c|}{6 months } \\
\hline Identification & $\begin{array}{c}\text { Animal B, device 6, 80 } \\
\text { threads }\end{array}$ & $\begin{array}{c}\text { Animal C, device 9,80 } \\
\text { threads }\end{array}$ & $\begin{array}{c}\text { Animal D, device 13, 96 } \\
\text { threads }\end{array}$ & $\begin{array}{c}\text { Animal E, device 16, 80 } \\
\text { threads }\end{array}$ & $\begin{array}{c}\text { Animal F, device 20, 56 } \\
\text { threads }\end{array}$ \\
\hline Endothelialization & 4 & 4 & 3 & 4 \\
\hline Side branch patency & 4 & - $^{* *}$ & No side branches & 4 \\
\hline
\end{tabular}

Table 6: SEM Evaluation* ( ${ }^{*}$ Evaluated on a 5-point scale: $0=$ absence; $1=$ slight, $2=$ moderate, $3=$ marked; $4=$ severe/full, ** The orientation of the side branch in this specimen resulted in a difficult analysis.).

of macrophagic reaction, and there was a slight grade of neointimal hyperplasia.

Following 1 month of implantation, the 80-96 thread devices were completely integrated into the vessels with a moderate grade of endothelialization. There was a slight grade of inflammatory reaction and a slight to moderate grade of neointimal hyperplasia. After 3 months of implantation, the 80-96 thread devices were completely integrated into the vessels with a moderate grade of endothelialization. A small amount of thrombus was observed. A slight to marked grade of inflammation was observed, with 3 specimens showing a marked grade of macrophagic reaction, and there was a moderate grade of neointimal hyperplasia. After 6 months of implantation, the 80-96 thread devices were completely integrated into the vessels with a moderate grade of endothelialization. Complete patency was not observed in all specimens from the 80-96 thread implants at 6 months, as 2 of the 7 specimens (as explained device 23 was excluded from the study) had reduced patency. Slight thrombus deposits were observed and the neointimal thickness did not significantly change compared to the findings after 1 month and 3 months of implantation. The 80-96 thread devices exhibited more signs of vessel injury and inflammation than the 56 thread devices although the degree of neointimal thickening appeared similar. In the specimens from the 80-96 thread implants at 6 months, there was an overall sub-moderate grade of macrophagic reaction, with 2 of the 7 specimens showing a marked grade, and there was a sub-moderate grade of neointimal hyperplasia.

\section{Histomorphometry analysis}

Table 5 presents the mean values from the quantitative histomorphometric analysis. Mean percentage stenosis for the 56 thread devices was $16.9 \pm 5.1 \%$ at 3 months and $21.7 \pm 9.9 \%$ at 6 months, with neointimal thickness of $252.4 \pm 87.3 \mu \mathrm{m}$ at 3 months and $311.3 \pm 162.7$ $\mu \mathrm{m}$ at 6 months. A Mann \& Whitney analysis was carried out and a value of $\mathrm{p} \leq 0.05$ was considered statistically significant. No statistically significant difference was observed between the 3-month and 6-month time intervals for the 56 thread devices.

Mean percent age stenosis for the 80-96 thread devices was 29.3 $5 \pm 10.4 \%$ at 1 month, $33.4 \pm 10.2 \%$ at 3 months, and $33.6 \pm 12.4 \%$ at 6 months, with neointimal thickness of $482.8 \pm 198.1 \mu \mathrm{m}$ at 1 month, $460.6 \pm 232.1 \mu \mathrm{m}$ at 3 months, and $448.8 \pm 206.4 \mu \mathrm{m}$ at 6 months. The percentage stenosis was significantly higher for the 80-96 thread devices than for the 56 thread devices at both 3 months $(\mathrm{p}=0.001)$ and 6 months $(p=0.004)$ duration of implantation. The neointimal thickness was also significantly higher for the 80-96 thread stents than for the 56 thread devices at both 3 months $(\mathrm{p}=0.034)$ and 6 months $(\mathrm{p}=0.032)$. Differences between the groups in terms of neointimal area were not significant at either 3 months or 6 months.

A mean device-to-artery diameter ratio of $1.16 \pm 0.15$ was calculated across all implanted devices (Table 2). For the 56 thread device group, the mean device-to-artery ratio was $1.17 \pm 0.11$ for the 1 month implantations, $1.15 \pm 0.08$ for the 3 month implantations, and $1.06 \pm 0.1$ for the 6 month implantations. For the 80-96 thread device group, the mean device-to-artery ratio was $1.17 \pm 0.06$ for the 1 month implantations, $1.23 \pm 0.08$ for the 3 month implantations, and $1.21 \pm 0.22$ for the 6 month implantations. Mann \& Whitney analysis was conducted andthe device-to-artery diameter ratiowas significantly related to both percentage stenosis $(\mathrm{p}=0.0001)$ and neointimal thickness $(\mathrm{p}=0.0001)$.

\section{SEM examination}

In the SEM examination of 5 selected specimens, ultrastructural analysis showed that all specimens analyzed after 3 and 6 months (56 and 80-96 thread devices) were markedly to fully endothelialized (Table 6). The orientation of the side branch in one specimen (animal C, device 9,80 threads) resulted in a difficult analysis. One specimen (animal D, device 13, 96 threads) did not have a side branch. The side branches in the remaining specimens were patent. Examples of the ultrastructural images for the 5 specimens are shown in Figure 2.

\section{Discussion}

This study assessed the biocompatibility of the MFM device in porcine animal models, focusing on the differential impact of design thread count and duration of device implantation. It should be noted that the animals were injected with non-fractionated heparin only at implantation $(70 \mathrm{UI} / \mathrm{kg})$ and at sacrifice $(90 \mathrm{UI} / \mathrm{kg})$. No anticoagulant/ antiplatelet drug was administered to the animals through the duration of the implantations.

For almost all implanted devices (with the exception of device 23), no major difficulty was encountered during placement. The devices were correctly delivered and deployed to the target sites. Of the 25 devices studied (after exclusion of device 23), there were 2 for which deployment required balloon angioplasty, due to incomplete expansion in the distal section of the device. The adjunctive angioplasty resulted in total expansion of the devices. In the instance of the deployment of device 19 in animal $\mathrm{F}$, there was an accidental dissection of the right 
Citation: Sultan S, Kavanagh EP, Bonneau M, Kang C, Alves A, et al. (2014) Assessment of Biocompatibility of the Multilayer Flow Modulator with Differing Thread Designs. J Vasc Med Surg 2: 167. doi: 10.4172/2329-6925.1000167

Page 6 of 8

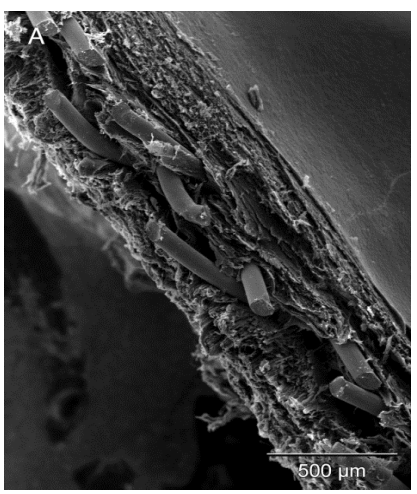

Figure 2a: SEM ultrastructural examination of specimens from 5 selected explants (Animal B, device 6, 80 thread).

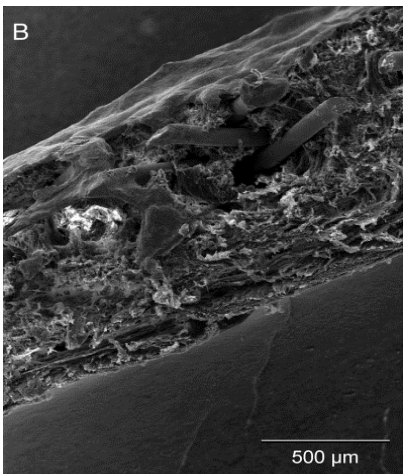

Figure 2b: SEM ultrastructural examination of specimens from 5 selected explants (Animal C, device 9, 80 threads).

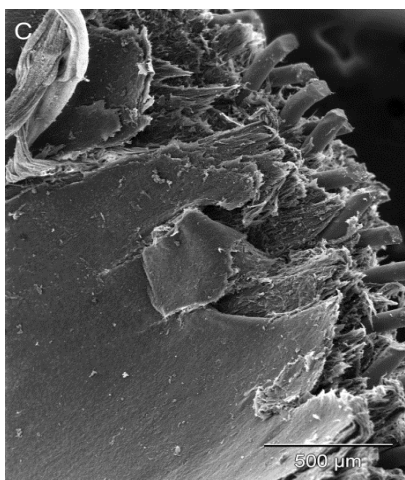

Figure 2c: SEM ultrastructural examination of specimens from 5 selected explants (Animal D, device 13, 96 threads)

femoral during arterial puncture for placement of the introducer, but the device was implanted successfully, and the incident was not considered to be device related.

Overall, the mean device-to-artery ratio was $1.16 \pm 0.15$. While low values were recorded in each group confirmed minimal over sizing of the devices overall, the statistical analysis still showed that the deviceto-artery ratio had a significant effect on the rates of stenosis and neointimal thickening.

On gross examination the 56 thread devices, implanted for durations of both 3 months and 6 months were well tolerated locally and yielded fewer signs of inflammation and neointimal hyperplasia than the 80-96 thread devices. The 80-96 thread devices showed a trend of eliciting greater signs of local inflammation, particularly at the late healing stage, when compared to the 56 thread devices.

Since animal A died on the table during the final angiographic follow-up, it was not possible to calculate stenosis percentages in the short term (1 month) for the 56 thread stents. Comparing the results for all the devices implanted for 3 months duration, the mean percentage stenosis for the 56 thread devices $(16.9 \pm 5.1 \%)$ was roughly half that for the 80-96 thread devices $(33.4 \pm 10.2 \%)$. The trend was similar for neointimal thickness at 3 months: $252.4 \pm 87.3 \mu \mathrm{m}$ for the 56 thread devices versus $460.6 \pm 232.1 \mu \mathrm{m}$ for the $80-96$ thread devices. Considering all the devices implanted for 6 months duration, the differences were not as large between the 2 device thread groups but still significant. At 6 months, mean percentage stenosis was 21.7 $\pm 9.9 \%$ for the 56 thread devices versus $33.6 \pm 12.4 \%$ for the $80-96$ thread devices, while neointimal thickness was $311.3 \pm 162.7 \mu \mathrm{m}$ versus $448.8 \pm 206.4 \mu \mathrm{m}$. It should also be noted that devices 2 and 4 (which required balloon angioplasty) did not have significantly higher values of percentage stenosis and neointimal hyperplasia. Overall, the lower mesh porosity of the 80-96 thread devices resulted in a significantly greater inflammatory response and neointimal hyperplasia formation. Despite the outcome differences between the 56 thread devices and the 80-96 thread devices, the values for both groups of devices remained within the normal range for stented carotid, kidney, or iliac arteries.

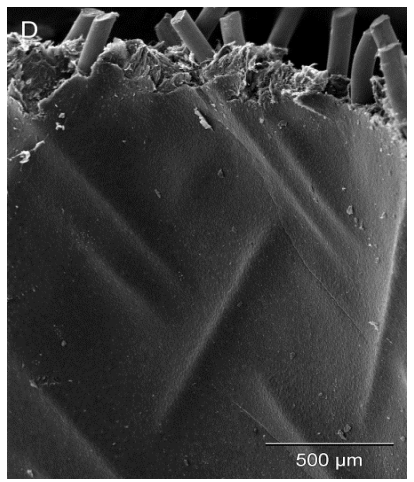

Figure 2d: SEM ultrastructural examination of specimens from 5 selected explants (Animal E, device 16, 80 threads).

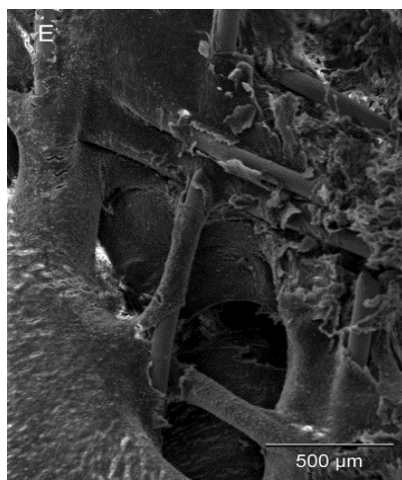

Figure 2e: SEM ultrastructural examination of specimens from 5 selected explants (Animal F, device 20, 56 threads). 
Stenosis levels below $50 \%$ are generally in an acceptable range for arterial function; even in the range of $40 \%$ to $50 \%$ stenosis, re-intervention is often not required, given that there is no significant narrowing of the arteries. Stenosis above $50 \%$ typically does require re-intervention.

The SEM examination showed that all 5 selected devices were well deployed and integrated into the vessel wall and endothelialized, with patent side branches (Table 6). With all devices placed in an iliac artery, the neck of the collateral artery (iliac circumflex) covered by the device always remained open.

This study demonstrates that there are differences in vessel reaction depending on thread number. It could therefore be hypothesized that the use of different thread numbers in the MFM may be suitable for different pathologies. For example could a 56 thread device be utilized for arterial occlusive disease due to minimal intimal hyperplasia/ restenosis? Or could the 80-96 thread device be utilized for aneurysmal disease due to its rapid endothelialization and encouragement of thrombus formation? Further research using different animals models such as aneurysm or dissection models may test this theory in vessel response.

Animal models are commonly used as a first-step method of assessment for new endovascular technologies [12-14]. Our study followed in line with the use of histology, histomorphometry, and SEM analysis, methods that have long been acknowledged as valuable tools forevaluating the biocompatibility of vascular endoprosthesis. Parameters such as endothelialization, intimal tissue formation and thickness, and inflammatory cell response were all used as indicators for biocompatibility. As in previous animal studies [12-14], technical success was evaluated and achieved in terms of device placement within the arteries of interest. Our study only examined normal healthy arteries free of stenosis or aneurysm, and did not perform implantation in stenotic or aneurysmal arteries.

Clinical results have been published on the MFM device used to treat aortic, peripheral and visceral aneurysms [7-9,15-17]. However, there is paucity of long-term data in relation to this new device, with current literature reporting relatively short follow up results [15-17]. When conducted strictly in accordance with the device instructions for use (IFU), deployment of the MFM has produced consistently positive outcomes in aortic pathologies including TAAA and aortic type B dissections $[7-9,15]$. The preliminary results of this study compare favorably with the current clinical findings, given the evidence for endothelialization and integration of the device into the artery.

\section{Conclusions}

In this evaluation of the biocompatibility of the MFM device in porcine animal models, no significant stenosis formation or inflammatory response was recorded in any of the implanted animals. The 80-96 thread devices elicited a greater intra-arterial response than the 56 thread devices, although the values for both groups remained within the normal range for stented carotid, kidney, or iliac arteries.

Irrespective of what thread number is used for the MFM, this study proved biocompatibility, endothelialization and integration of the MFM into the vessel wall. Preclinical studies are central as a basis for continuous translational research on the fundamental mechanisms of action of the MFM. Due to the paucity of long-term data, further studies with a larger cohort are needed to complete assessment of the long-term efficaciousness of the MFM.

\section{Limitations of the Study}

This preclinical study was limited by the use of young and otherwise healthy porcine test animals. The results showed that the devices were mostly positioned and deployed without any difficulty in the test animal arteries. But these were not comparable to the often tortuous and/or calcified vessels found in older human beings. Animal studies are limited by design, in that they often automatically control many variables that are beyond control in normal human surgical situations [18]. Animal studies do not include naturally occurring variation [19].

\section{Acknowlegement}

This study was sponsored by Cardiatis (Isnes, Belgium).

\section{References}

1. Lioupis C, Corriveau MM, Mackenzie KS, Obrand DI, Steinmetz OK, et al. (2011) Paraplegia prevention branches: a new adjunct for preventing or treating spinal cord injury after endovascular repair of thoracoabdominal aneurysms. $J$ Vasc Surg 54: 252-257

2. Nordon IM, Hinchliffe RJ, Manning B, Ivancev K, Holt PJ, et al. (2010) Toward an "off-the-shelf" fenestrated endograft for management of short-necked abdominal aortic aneurysms: an analysis of current graft morphological diversity. J Endovasc Ther 17: 78-85.

3. Sultan S, Hynes N (2012) Disruptive endovascular technology with Multilayer Flow Modulator stents as a therapeuticoption in the management of thoracoabdominal aortic aneurysms. Early results from the global independent MFM Regsitry. Ital J Vasc Endovasc Surg 19: 215-218.

4. Henry M, Polydorou A, Frid N, Gruffaz P, Cavet A, et al. (2008) Treatment of renal artery aneurysm with the multilayer stent. J Endovasc Ther 15: 231-236.

5. Meyer C, Verrel F, Weyer G, Wilhelm K (2011) Endovascular management of complex renal artery aneurysms using the multilayer stent. Cardiovasc Intervent Radiol 34: 637-641.

6. Ferrero E, Ferri M, Viazzo A, Robaldo A, Carbonatto P, et al. (2011) Visceral artery aneurysms, an experience on 32 cases in a single center: treatment from surgery to multilayer stent. Ann Vasc Surg 25: 923-935.

7. Sultan S, Hynes N (2013) One-year results of the multilayer flow modulator stent in the management of thoracoabdominal aortic aneurysms and type B dissections. J Endovasc Ther 20: 366-377.

8. Chocron S, Vaislic C, Kaili D, Bonneville JF (2011) Multilayer stents in the treatment of thoraco-abdominal residual type B dissection. Interact Cardiovasc Thorac Surg 12: 1057-1059.

9. Sultan S, Sultan M, Hynes N (2014) Early mid-term results of the first 103 cases of multilayer flow modulator stent done under indication for use in the management of thoracoabdominal aortic pathology from the independent global MFM registry. J Cardiovasc Surg (Torino) 55: 21-32.

10. Higgs ZC, Macafee DA, Braithwaite BD, Maxwell-Armstrong CA (2005) The Seldinger technique: 50 years on. Lancet366:1407-1409.

11. Donath K, Brunner G (1982) A method for the study of nondecalcified bone and teeth with attached soft tissues. J Oral Pathol Med 11: 318-326.

12. Froelich JJ, Alfke H, Wilke A, Ramaswamy A, Barth KH, et al. (1999) Effects of nitinol Strecker stent placement on vascular response in normal and stenotic porcine iliac arteries. J Vasc Interv Radiol 10: 329-338.

13. Whelan DM, van der Giessen WJ, Krabbendam SC, van Vliet EA, Verdouw PD, et al. (2000) Biocompatibility of phosphorylcholine coated stents in normal porcine coronary arteries. Heart 83: 338-345.

14. Galloni M, Prunotto M, Santarelli A, Laborde F, Dibie A, et al. (2003) Carboncoated stents implanted in porcine iliac and renal arteries: histologic and histomorphometric study. J Vasc Interv Radiol 14: 1053-1061.

15. Vaislic C, Fabiani J, Chocron S, Robin J, Costache V, et al. (2014) One-yea outcomes following repair of thoracoabdominal aneurysms with the Multilayer Flow Modulator: report from the STRATO trial. J Endovasc Ther 21: 85-95.

16. Polydorou A, Henry M, Bellenis I, Kiskinis D, Bolos K, et al. (2010) Endovascular treatment of arterial aneurysms with side branches - a simple method. Myth or reality?Hospital Chronicles 5: 88-94. 
Citation: Sultan S, Kavanagh EP, Bonneau M, Kang C, Alves A, et al. (2014) Assessment of Biocompatibility of the Multilayer Flow Modulator with Differing Thread Designs. J Vasc Med Surg 2: 167. doi: 10.4172/2329-6925.1000167

Page 8 of 8

17. Balderi A, Antonietti A, Pedrazzini F, Sortino D, Vinay C, et al. (2013) Treatment of visceral aneurysm using multilayer stent: two-year follow-up results in five consecutive patients.Cardiovasc Intervent Radiol 36: 1256-1261.

18. Hackam DG, Redelmeier DA (2006) Translation of research evidence from animals to humans. Jama 296: 1731-1732.
19. Williams SM, Haines JL, Moore JH (2004) The use of animal models in the study of complex disease: all else is never equal or why do so many human studies fail to replicate animal findings? Bioessays 26: 170-179. 